Volume: 13 Issue: 3 Year: 2016

\title{
Development of Instrument Performance Self-Efficacy Scale \\ Çalg1 Performansına İlişkin Öz-Yeterlik Ölçeğinin geliştirilmesi
}

\section{Sadullah Serkan Şeker ${ }^{1}$}

\begin{abstract}
The aim of this study is to develop a valid and reliable scale that can be used in determining preservice music teacher's self-efficacy beliefs towards instrumental performance. The first step of this study is to get an expert view about items. After this process the scale was administrated 443 preservice music teachers and explanatory factor analysis was applied. According to EFA results, the scale was consisted of three sub-dimensions that are called "self-efficacy towards instrumental performance", "negative emotions felt in instrumental practicing" and "modeling". The cronbach alpha coefficients of this three sub dimension are found, 85 for the first factor, 82 for second factor and, 76 for third factor. The scale along with its three sub-dimensions are accounted for 52,5 percent of total variance. After EFA, DFA was applied for new data set that was consisted of 275 preservice teachers. According to DFA results, it is understood that the model showed great fit $(\mathrm{x} 2=283.52$, DF =148). After DFA, convergent validity was applied using "Self-efficacy beliefs toward instrumental performance scale developed by Girgin (2015). Correlation coefficient ( $\mathrm{r}=65$, $\mathrm{p}<0,01)$ shows that those two scales show high convergence each other. The last stage in the developmental process is test re-test analysis. For this analysis scale was administrated same group ( $\mathrm{n}=68) 17$ days apart. The correlation coefficient shows that the scale shows high consistency when it was administrated different time periods $(\mathrm{r}=88, \mathrm{p}<0,01)$.
\end{abstract}

Özet

$\mathrm{Bu}$ çalışmanın amacı eğitim fakültesi güzel sanatlar eğitimi bölümü müzik eğitimi anabilim dallarında öğrenim görmekte olan öğretmen adaylarının çalgısal performanslarına ilişkin özyeterlik düzeylerinin belirlenmesine yönelik geçerli ve güvenilir bir ölçme aracı geliştirmektir. Ölçek geliştirilme aşamasında öncelikle uzman görüşüne başvurulmuş ön deneme formu hazırlandıktan sonra 443 kişilik katılımc1 grubuna uygulanarak açımlayıcı faktör analizi yapılmıştır. Açımlayıcı faktör analizi sonucunda ölçeğin "çalg1 performansına yönelik öz-yeterlik inancı", "çalg1 çalışma sırasında hissedilen negatif duygular" ve "model alma" olmak üzere üç alt boyuta sahip olduğu görülmüş, üç alt boyutun total varyansın \% 52,5'ini açıkladığ1 belirlenmiştir. Ölçek maddelerinin faktör yükleri ,45 ile ,98 arasında değişmektedir. Ölçeğin iç geçerlik katsayılan incelendiğinde ise "çalg1 performansına yönelik öz-yeterlik inancı"nın ,85, "çalg1 çalışma sırasında hissedilen negatif duygular"1n ,82 ve "model alma" alt boyutunun ise ,76 olduğu tespit edilmiştir. Ölçeğe yapılan doğrulayıc1 faktör analizi sonucunda oluşturulan modelin $\mathrm{x} 2=283.52 \mathrm{df}=148$ olduğu tespit edilmiş $\mathrm{x} 2 / \mathrm{df}$ oranının $(1,91)$ modelin iyi uyum sergilediğini temsil ettiği görülmüştür. Geliştirilen ölçeğin daha sonra benzer ölçek geçerliği analizleri yapilmıs ve her iki ölçeğin toplam puanlanna ilişkin pozitif yönde kuvvetli ilişki gösterdiği ( $\mathrm{r}=, 651, \mathrm{p}<0,01)$ görülmüştür. son olarak ölçeğe test-tekrar test uygulanmış ve 17 gün arayla ölçeğin yüksek tutarlık gösterdiği görülmüştür $(\mathrm{r}=, 88, \mathrm{p}<0,01)$.

\footnotetext{
${ }^{1}$ Dr., Adnan Menderes Üniversitesi, Eğitim Fakültesi Güzel Sanatlar Eğitimi Bölümü Müzik Eğitimi Anabilim Dalı, sserkanseker@gmail.com
} 
Şeker, S. S. (2016). Çalg1 Performansına İlişkin Öz-Yeterlik Ölçeğinin geliştirilmesi. Journal of Human Sciences, 13(3), $5150-$ 5162. doi:10.14687/jhs.v13i3.3933

Keywords: Instrumental Performance; Self- Anahtar Kelimeler: Çalg1 Performans; Özefficacy; Validity; Reliability. yeterlik; Geçerlik; Güvenirlik.

(Extended English abstract is at the end of this document)

\section{GİRIŞ}

Çalg1 eğitimi, kısaca bireyin zihninde oluşturduğu müzikal ifadeleri çalgisı yoluyla dışavurumunu sağlama aşamasında gerekli olan müzikal ve teknik becerinin kazanılması süreci olarak tanımlanabilir. Akbulut (2013:58), çalg1 eğitimini genel ve mesleki müzik eğitiminin önemli bir boyutu olarak değerlendirmiş, çalgı eğitimini bireyin müzikle ilgili davranışlanı kazanmada, bilgi, beceri ve yeteneklerini geliştirmede ve müzikle daha içten bir bağ kurmada etkili bir süreç olduğunu belirtmiştir.

Çalg1 eğitiminin başarıya ulaşmasında kuşkusuz en büyük etkenlerden biri de çalg1 çalışma sürecidir. Özmenteş (2007:1) çalg1 çalışma sürecinin bireyin yetenek düzeyi ile birlikte bilişsel, duyuşsal, davranışsal ve sosyal açıdan yoğun bir çaba gerektirdiğini ifade etmiştir. Çalg1 çalışma sürecinin başarıya ulaşmasında iki temel etken çalg1 çalışmaya ayrılan süre ve bu sürenin birey tarafindan nasıl yapılandırıldığıdır. Literatürde pek çok araştırmacı farklı düzeydeki müzisyenler için bireysel ve pratik yapma konusunda yoğun bir zaman geçirdiklerine dikkat çekmişlerdir (McPherson, 2005, Sloboda, Davidson, Howe ve Moore, 1996; Sosniak; Byo ve Cassidy, 2008, Jorgensen, 1997; Miksza, 2015:219). Buna karşın Rohwer \&Polk, (2006) ve Miksza, (2015) pratiğe harcanan zaman miktarının performans başarılarında tamamen bir belirleyici olmadığının farkına varılmasının önemli olduğu belirtmişlerdir. Yapılan pratiğin verimliliği ve etkililiği konusunda Ericsson, Krampe ve Römer (1993) planlı çalışma (deliberate practise) kavramını öne sürmektedirler. Bireylerin ulaştıkları performans düzeyinin doğrudan yaptıkları amaçlı çalışmalara bağlı olduğunu belirten Ericsson ve arkadaşları, amaçlı çalışmayı bireylerin acemilikten uzmanlığa kadar geçen sürede içindeki gelişimini tanımlayan bir çalışma şekli olduğunu vurgulamışlardır. Buna göre amaçlı çalışma, performansı en iyi düzeye ulaştırma konusunda kullanılması gereken taktik ve stratejileri içermektedir. McCormick ve McPherson (2003:38) çalgı çalıșma sürecinde bilişsel ve bilișüstü stratejilerin kullanımına dikkat çekmiş, matematik ve diğer bilim dallarındaki öz-düzenleme uygulamalarının müzikal çalışmalara da uygulanabileceğini belirtmişlerdir.

Pintrich ve De Groot, (1990:33) biliş ve bilişüstü bilginin genel olarak öğrenci başarısını arttırmada tek başına yeterli olmayacağını, süreç içinde öğrencinin bu stratejileri etkili bir biçimde kullanabilmesi için motive olması gerektiğini belirtmişlerdir. Söz konusu motivasyonel öğelerden birisi de kişinin kendi kapasitesine olan inancını temsil eden öz-yeterlik algısıdır.

Bandura'nın sosyal bilişsel teorisinin önemli bir parçası olan öz-yeterlik, kişinin belirli bir performansa ulaşmak için gerekli olan davranışların organizesi ve gerçekleştirilmesine ilişkin kendi kapasitesine olan inancı olarak tanımlanmaktadır (Pajares, 1996:544). Schunk ve Pajares (2001) özyeterliği bireyin öğrenebilme ya da belirli bir görevin üstesinden gelebilmesine ilişkin kişisel inançları olarak tanımlamışlardır.

Öz-yeterlik kavramı performanslarda belirgin olarak ortaya çıan bir kavram olduğu için kritik öneme sahiptir (Bandura, 1977). Öz-yeterlik ve diğer beklenti teorileri kişilerin becerilerine ilişkin algıları noktasında ortaktırlar. Fakat öz-yeterlik kişilerin belirlenmiş performanslara ulaşmaları ve belirli sonuçlara ulaşmaları noktasında diğer teorilerden ayrılmaktadır (Pajares, 1996:546). Diğer 
beklenti teorilerine göre öz-yeterlik yargıları daha fazla görev ve durum özellikli olabilir ve bireyler bu yargıları bazı belirli amaçlara ulaşma yolunda referans olarak kullanabilirler (Bandura, 1986; Pajares, 1996). Benzer şekilde müzisyenlerin çeşitli koşullar altında ya da belirli limitler altında gösterecekleri performanslar ile ilgili sahip olduğu düşünceler tamamen öz-yeterlik yarg1ları ile ilgilidir. Çünkü bu tip durum özellikli yarg1lar müzisyenlerin performans sergilemelerine ilişkin etkileri açısından sahip oldukları en güçlü yargılardır (McPherson ve McCormick, 2006:323).

Akademik alan yazın incelendiğinde öz-yeterliğin matematik alanında bir zihinsel beceri olarak güçlü bir performans belirleyicisi olduğu görülmektedir (McPherson ve McCormick, 2006). Bu alanda yapılan diğer çalışmalarla birlikte (Pajares ve Miller, 1994; Jinks ve Lorsbach, 2003) öz yeterlik, eğitim psikologları tarafından bireylerin başarıya giden davranışlarının motivasyonu özellikle de davranışlardaki süreklilik boyutu ile ilgili olarak akademik başarının "öncül” belirleyicisi olarak görülmüştür (McPherson ve McCormick, 2006:333). Pajares, Hartley ve Valiante (2001), öğrencilerin kendi becerilerine ilişkin güvenlerinin azlığında söz konusu becerileri gerektiren görevleri üstlenme olasılıklarının azaldığını, göreve ilişkin herhangi bir zorlukla karşılaştıklanında görevi kolaylıkla bırakabildiklerini belirtmişlerdir. Benzer sonuçlara Özmenteş, (2007) nin araştırma bulgularında rastlanmıştır. Elde edilen bulgulara göre öğrencilerin çalg1 çalışma sürecindeki özdüzenlemeli öğrenme düzeylerine etki eden önemli değişkenlerden birisi de müzikal yeteneklerine ilişkin öz-yeterlik inançlarıdır. Aynı şekilde McCormick ve McPherson (2003) araştırmalarında özyeterliğin performansı doğrudan etkileyen önemli bir değişken olduğunu belirtmişlerdir.

Öz-yeterlikle ilgili bir diğer önemli nokta öz-yeterliğin ölçülmesi konusudur. Bandura (2006:307) özyeterliği ölçmeye ilişkin çok amaçlı bir ölçüm yapılamayacağını, ölçmede kullanılan "çok amaçlı" maddelerin belirli bir alan hakkında çok az bilgi verebileceğini ya da tamamen ilgisiz olacağını, dolayısıyla bu tür bir yaklaşımın çok sınırlı bir açıklayıcı ya da belirleyici bilgi vereceğini, çok amaçlı ölçümlerde kullanılan maddelerdeki terimlerin belirli alanları ya da koşulları karşılamayacağını, dolayısıyla elde edilen ölçümlerim karmaşık olabileceğini belirtmiştir. Bu nedenle kullanılacak olan ölçme aracının ilgili alanın özelliklerine göre hazırlanması gerektiğini vurgulamıştır.

Ulusal alan yazın incelendiğinde çalgısal performansa ilişkin öz yeterlik düzeyini ölçmeye ilişkin az sayıda ölçme aracı geliştirildiği görülmektedir. Yapılan literatür taramasında çalg1 performansı öz yeterlik inancı ölçeği (Girgin, 2015), piyano performans öz yeterlik ölçeği (Gün ve Yıldız, 2014), keman çalmaya yönelik öz-yeterlik ölçeği (Yıldırım, 2009) gibi belirli bir çalgıya yönelik performanslara ilişkin öz-yeterlik ölçeklerinin bulunduğu görülmektedir. Buna karşın söz konusu alanda geçerli ve güvenilir ölçme araçlarının sayıca fazla olması çalg1 performansına ilişkin özyeterlik düzeyinin daha geniş bir perspektifte incelenmesine ve bu spesifik öz-yeterlik alanını etkileyen değişkenlerin neler olabileceğine ilişkin daha net çözümlemeler yapılabilmesine olanak tanıyabilecektir. Bu doğrultuda yapılan araştırmanı amacı, çalgı performansına ilişkin öz-yeterlik algılarını ölçmeye yönelik geçerli ve güvenilir bir ölçme aracı geliştirmektedir.

\section{YÖNTEM}

Ölçme aracını geliştirme süreci kapsam geçerliği (uzman görüşü), madde analizi, açımlayıcı faktör analizi, doğrulayıcı faktör analizi, güvenirlik analizi, test-tekrar test ve benzer ölçek geçerliği analizlerinden oluşmaktadır.

İlk olarak müzik eğitimi literatüründeki ve diğer alanlardaki öz-yeterlik ölçekleri incelenmiş (Girgin, 2015; Gün ve Yıldız, 2014; Zelenak, 2011;Yıldırım, 2009; Özmenteş, 2008) tir. Daha sonra ölçeklerdeki ifadeler ve öğretmen adayları ile yapılan görüşmeler sonucunda 26 maddelik bir ön form oluşturulmuştur. Ölçme aracını tasarımı Bandura (2006)'nın görüşleri doğrultusunda 
hazırlanmış katılımcıların maddelere ilişkin cevaplarını 0-10 puan aralı̆̆ında cevaplayabilecekleri bir şekilde tasarlanmıştır. Bandura (2006) bu tip bir ölçme aracının 5'li likert ölçek yapısına göre daha hassas ve güvenilir ölçüm yapabildiğini belirtmiştir. Hazırlanan ön form ikisi rehberlik ve psikolojik danışmanlık ve iki müzik eğitimi alanında olmak üzere toplam dört uzmanın görüşüne sunulmuştur. Görüşler doğrultusunda 4 madde ölçeğe dahil edilmemiş ve 22 maddeden oluşan ön deneme formu elde edilmiştir. Maddelerin 7'si olumsuz maddedir. Madde havuzundaki maddeler, öğrencilerin çalgılarına ilişkin performanslarına dair inançları, geçmişteki çalgısal deneyimlerinin şu ana dair performanslarına olan etkilerine dair inançlarını, çevrelerindeki kişilerin alınan dönütlerin çalgısal performanslarına ilişkin inançlarını ve çalgı çalışma sırasındaki hissedilen negatif duygu durumlarına ilişkin maddeleri kapsamaktadır.

Oluşturulan ön deneme formu 2014-2015 güz döneminde başta Adnan Menderes Üniversitesi olmak üzere Balıkesir Üniversitesi, Pamukkale Üniversitesi ve Dokuz Eylül Üniversitesi Eğitim Fakülteleri Güzel Sanatlar Eğitimi Bölümü Müzik Eğitimi Anabilim Dallarından 1. Sınıf, 2. Sınıf, 3. Sınıf ve 4. Sınıf olmak üzere toplam 462 kişilik katılımcı grubuna uygulanmıştır. Formlar incelenerek eksik ya da uygunsuz doldurma yapan 19 katılımcının formu analiz dışında bırakılmıştır. Analize dahil edilen 443 kişilik katulımcı grubuna ait betimsel istatistikler tablo 1'de verilmiştir. Analiz aşamasında ilk olarak madde analizi gerçekleştirilmiş, 22 maddenin maddeler arası (inter-item correlation) ve madde toplam korelasyonları (item-total correlation) incelenmiştir. yapılan incelemeler sonucunda 3 maddenin madde toplam korelasyonlarının yeterli düzeyde olmadığ1 görülmüş ve ölçekten çıkartılmasına kara verilmiştir. Bu süreçte ölçek toplamda 19 maddeye indirgenmiştir.

Analizin devamında elde edilen 19 maddelik ölçeğe açımlayıcı faktör analizi uygulanmıştır. Faktör analizi, birbiriyle ilişkili p tane değişkeni bir araya getirerek az sayıda ilişkisiz ve kavramsal olarak anlamlı yeni değişkenler (Faktörler, boyutlar) bulmayı, keşfetmeyi amaçlayan çok değişkenli bir istatistiktir (Büyüköztürk, 2007;123). Açımlayıcı faktör analizinde maddelerin faktör yük değerlerine kesme noktas1 40 olarak belirlenmiştir. Tabachnick ve Fidell'e (2001) göre temel bir kural olarak her bir değişkenin faktör yük değerinin 0.32 ve daha üzerinde olması gerekir. Comrey ve Lee (1992), bir yük değerinin, 0.71 olması halinde (varyansın \% 50'sini açıklar) "mükemmel", 0.63 olması halinde (varyansın \% 40'ını açılkar) "çok iyi", 0.55 olması halinde (varyansın \% 30'unu açıklar) "iyì", 0.45 olması halinde (varyansın \% 20'sini açıklar) "vasat" ve 0.32 olması halinde (varyansın \% 10'unu açıklar) "zayıf " olarak değerlendirilmesi yönünde öneri getirmişlerdir (akt., Tabachnick ve Fidell, 2001). Bu nedenle bu çalışmada maddelerin ölçekte kalmasına karar vermede alt sınır olarak 0.40 benimsenmiştir.

Tablo 1. Katıllımcı Gruba İlişkin Betimleyici İstatistikler

$\begin{array}{cc}\mathrm{n} & \% \\ 176 & 39,7 \\ 267 & 60,3 \\ 443 & 100 \\ & \\ 126 & 28,4 \\ 211 & 47,6 \\ 106 & 23,9 \\ 443 & 100 \\ & \\ 132 & 29,8 \\ 83 & 18,7 \\ 106 & 23,9 \\ 99 & 22,3\end{array}$




\begin{tabular}{ccc} 
5. Sinıf ve üzeri & 23 & 5,2 \\
Toplam & 443 & 100 \\
Okul & & \\
Adnan Menderes Ün. & 114 & 25,7 \\
Balıkesir Ün. & 102 & 23 \\
Pamukkale Ün. & 110 & 24,8 \\
Dokuz eylül Ün. & 117 & 26,4 \\
Toplam & 443 & 100 \\
\hline
\end{tabular}

Açımlayıcı faktör analizinden sonra ölçeğe doğrulayıcı faktör analizi uygulanmıştır. Doğrulayıcı faktör analizi (DFA) ise kuramsal bir temelden destek alarak pek çok değişkenden (göstergelerden; indicators) oluşturulan faktörlerin(gizil değişkenlerin; latent variables) gerçek verilerle ne derece uyum gösterdiğini değerlendirmeye yönelik bir analizdir. Bir başka anlatımla DFA, önceden belirlenmiş ya da kurgulanmış bir yapının toplanan verilerle ne derece doğrulandığını incelemeyi amaçlar (Büyüköztürk, Akgün, Özkahveci Demirel, 2004). DFA'nın tamamen geliştirilmesi Karl Jöreskog tarafindan sağlanmış, tanımlı bir yapının maddelerinin oluşturduğu veri setinin test edilip edilemeyeceğine ilişkin kuramsal çalışmaları ile DFA'yı geliştirmiştir (Çelik ve Yılmaz, 2013). Katulıcı gruba ilişkin betimsel istatistikler tablo 5'te sunulmuştur. Doğrulayıcı faktör analizi için ayrı bir veri seti oluşturulmuştur. Bu veri seti 2014-2015 eğitim öğretim güz yarıyllnda Adnan menderes Üniversitesi, Sttk1 Koçma Üniversitesi ve Mehmet Akif Ersoy Üniversitesi Eğitim Fakülteleri Güzel sanatlar Eğitimi Bölümleri Müzik Eğitimi Anabilim dallarından 1. Sınıf, 2. Sınıf, 3. Sınıf ve 4. Sınıf olmak üzere toplam 281 öğretmen adayına ulaşlmış, formlar incelenerek uygunsuz ve eksik doldurma yapan 6 katılımcının formu geçersiz sayılmıstır. 275 katılımcıya ilişkin betimsel istatistikler tablo 5’Te sunulmuştur.

Doğrulayıc1 faktör analizinden sonra elde edilen ölçeğin iç tutarlık kat sayıları incelenmiş ve ölçeğe benzer ölçek geçerliği uygulanmıştır. Bu analiz için Girgin (2015) tarafinda geliştirilip geçerlik ve güvenirlik çalışmaları yapılan çalg1 performans özyeterlik inancı ölçeği uygulanmıştır. Ölçek "Kendini yeterli görme", "Kendini yetersiz görme" ve "psikolojik göstergeler" olmak üzere 3 alt boyuttan oluşmaktadır. Birinci alt boyutun güvenirlik katsayıs1,86, ikinci alt boyutun güvenirlik katsayısı ,76 ve üçüncü alt boyutun güvenirlik katsayısı ise ,61 olarak rapor edilmiştir.

Son olarak ölçeğe farklı zamanlardaki uygulamalarda göstereceği tutarllğın ölçülmesi için test tekrar test yapılmıştır. Adnan Menderes Üniversitesi Eğitim Fakültesi Güzel Sanatlar Eğitimi Bölümünden toplam 68 katıllımcıya ölçek 17 gün arayla uygulanmıştır.

\section{BULGULAR}

Araştırmada ilk olarak ölçeğin yapı geçerliği incelemek için açımlayıcı faktör analizi ve daha sonra da doğrulayıcı faktör analizi uygulanmıştır. Her iki analiz için iki farklı veri toplanmıştır. Açımlayıcı faktör analizi için eldeki örneklemin yeterli olup olmadığının incelenmesi için Kaiser-Meyer-Olkin örneklem yeterliği değeri incelenmiş ve elde edilen ,921’lik sonuç doğrultusunda örneklemin açımlayıcı faktör analizi için uygun olduğu sonucuna varılmıştır. Bartlett küresellik testinde ise x2 = 2994,74 serbestlik derecesi ise 153 bulunmuştur.

Analizin devamında ölçeğin öz değeri 1'den büyük 3 alt faktöre sahip olabileceği ve bu 3 alt faktörün varyansın \% 53,5’ini açıkladığı görülmüş, her bir alt faktörün aldığı öz değerler ve yamaç birikintisi grafiği (şekil1) incelendiğinde ölçeğin 3 alt faktör altında toplanabileceği belirlenmiştir. Ölçek maddeleri arasındaki korelasyonun .20'nin üzerinde olmasından dolayı maddelerin birbirleri 
ile ilişki içinde olduklanı saptanarak temel bileşenler analizi yerine maximum likelihood ve rotasyonda varimax yerine direct oblimin yöntemi kullanılarak ölçek 3 faktöre döndürülmüştür. Şimşek (2007:100) temel bileşenler analizi ve varimax rotasyonun birbirleri ile daha az ilişkili maddeler de kullanılabileceğini belirtmiştir. Analiz sonucunda 19 maddeden oluşan ölçeğin açıklanan toplam varyansın \% 53,54 'ünü açıkladığ1 görülmüştür. Tablo 3’te elde edilen faktörler ve aldıkları yük değerleri verilmiştir.

Şekil 1. Yamaç grafiği

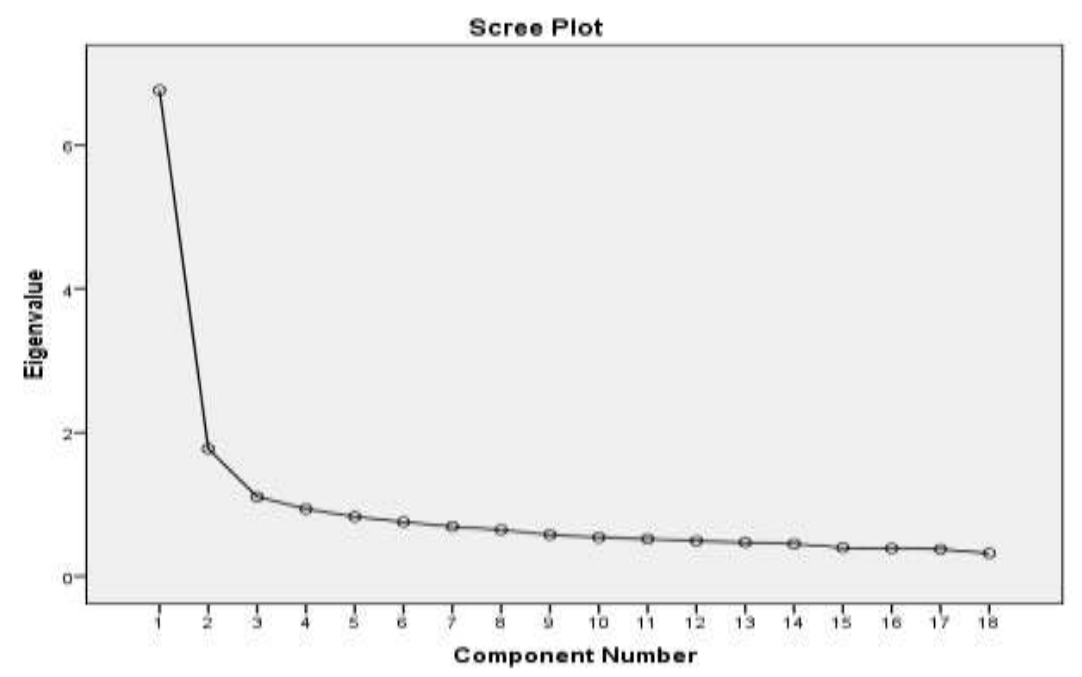

Tablo 3. Faktörler ve Faktör Yükleri

\begin{tabular}{|c|c|c|c|}
\hline & F1 & F2 & F3 \\
\hline M3 & 628, & & \\
\hline M4 & 609 & & \\
\hline M16 &, 599 & & \\
\hline M2 &, 569 & & \\
\hline M13 &, 547 & & \\
\hline M5 &, 517 & & \\
\hline M6 & ,453 & & \\
\hline M1 & ,484 & & \\
\hline M8 & ,456 & & \\
\hline M22 & & 695 & \\
\hline M21 & & ,985 & \\
\hline M24 & & ,702 & \\
\hline M19 & & 673 & \\
\hline M17 & &, 591 & \\
\hline M25 & &, 535 & \\
\hline M7 & & & ,735 \\
\hline M9 & & &, 524 \\
\hline M12 & & &, 539 \\
\hline M11 & & & ,473 \\
\hline KMO Değeri & & & 921 \\
\hline$X^{2}$ & & & 3190,90 \\
\hline$d f$ & & & 171 \\
\hline Faktör 1 Açıklanan Varyans (\%) & & & 36,677 \\
\hline Faktör 2 Açıklanan Varyans (\%) & & & 10,14 \\
\hline Faktör 3 Açılklanan Varyans (\%) & & & 5,82 \\
\hline Ölçeğin Tamamının Açıkladığı Toplam Varyans (\%) & & & 52,64 \\
\hline
\end{tabular}


Faktörlere ilişkin maddeler incelendiğinde 1. Faktör "Çalgısal performansa ilişkin öz-yeterlik algısı", 2. Faktör ise "Çalg1 çalışma sırasında hissedilen negatif duygu durumu" faktör 3 ise " model alma" olarak isimlendirilmiştir. 1. Faktör toplam varyansın 36,6'ini açıklarken 2. Faktör toplam varyansın 10,14' ünü açıklamaktadır. 3. Faktör ise varyansın 5,8'ünü açıklamaktadır. 3 faktörlü ölçeğin tamamının açıkladığı toplam varyans 52,64' dür. Faktörlerin iç geçerlikleri için Cronbach-Alpha katsayına bakılmış, 1. Faktörün Conbach-Alpha katsayısının ,85, 2. Faktörün ,83 olduğu belirlenmiştir. 3. Faktörün iç geçerlik katsayısı ise 76 dır. Elde edilen bu değerler, her bir faktörün yüksek iç geçerliğe sahip olduğunu belirtmektedir. Ölçeğin tümüne ilişkin Cronbach-Alpha iç tutarlılık katsayısı ise ,90 olarak belirlenmiştir. Ölçeğin faktörleri arasındaki korelasyon tablosu tablo 4’teverilmiştir.

Tablo 4. Faktörler arası Korelasyon

\begin{tabular}{llll}
\hline & $\mathbf{1}$ & $\mathbf{2}$ & $\mathbf{3}$ \\
\hline Çalgı Performansına İlişkin Öz-Yeterlik Algısı & 1 &,$- 506^{* *}$ &, $674^{* *}$ \\
Çalgı Çalışmaya İlişkin Negatif Duygu Durumu &,$- 506^{* *}$ & 1 &,$- 462^{* *}$ \\
Model Alma &, 674 &,$- 462^{* *}$ & 1 \\
\hline
\end{tabular}
${ }^{* *} \mathrm{p}>0,01, \mathrm{~N}=443$

Faktörler arası korelasyon incelendiğinde 1. Faktör ile 2. Faktörün negatif yönde kuvvetli ilişki içinde olduğu, faktör 1 ile faktör 3 'ün pozitif yönde kuvvetli ilişki içinde olduğu ve faktör 2 ile faktör 3’ün negatif yönde kuvvetli ilişki içinde olduklan belirlenmiştir.

Araştırmanın devamında doğrulayıcı faktör analizi ve yakın ölçek geçerliği analizi için ayrı bir veri seti hazırlanmıştur. Bu veri setinde toplam 275 kişilik katılımc1 grubuna ulaşılmış, betimleyici istatistikleri tablo 5’teverilmiştir.

Tablo 5. Doğrulayıcı Faktör Analizi İçin Toplanan Veri Setine İlişkin Betimsel İstatistikler

\begin{tabular}{ccc}
\hline & N & $\%$ \\
\hline Cinsiyet & 118 & 42,9 \\
Erkek & 157 & 57,1 \\
Kadın & 275 & 100 \\
Toplam & & \\
Yaş & 77 & 28 \\
$17-19$ & 152 & 55,3 \\
20-22 & 46 & 16,7 \\
23 ve üstü & 275 & 100 \\
Toplam & & \\
Sinıf & 54 & 19,6 \\
Lisans 1 & 75 & 27,3 \\
Lisans 2 & 71 & 25,8 \\
Lisans 3 & 67 & 24,4 \\
Lisans 4 & 8 & 2,9 \\
5. Sinıf ve üzeri & 275 & 100 \\
Toplam & & \\
Okul & 67 & 24,4 \\
Adnan Menderes Ün. & 114 & 41,5 \\
Sitk1 Koçman Ün. & 94 & 34,2 \\
Mehmet Akif Ersoy Ün. & 275 & 100 \\
Toplam & & \\
\hline
\end{tabular}

Elde edilen doğrulayıcı faktör analizi sonuçlarına göre RMSEA = 0,064 (\%90 Güven aralığ $=0,054$ $-0,074), \mathrm{CFI}=, 92, \mathrm{IFI}=, 92, \mathrm{AGFI}=, 87, \mathrm{GFI}=, 89$ ve $\mathrm{RMR}=, 31$ olarak bulunmuştur. Modelin $\mathrm{x}^{2}$ değeri 316.65 serbestlik deresi ise 149'dir. Alan yazında GFI ve AGFI Değerlerinin 1 Olmasının 
Mükemmel Uyum Göstergesi Olduğu Belirtilmektedir (Hooper, Coughlan Ve Mullen, 2008; Kelloway, 1989; Schumacker Ve Lomax, 1996; Sümer, 2000). Model incelendiğinde elde edilen değerlerin iyi uyumu işaret ettiği söylenebilir. Her ne kadar elde edilen değerler modelin uyum iyiliği için uygun olarak görülse de analiz sonunda verilen modifikasyon değerleri incelendiğinde daha iyi bir uyum yakalanabileceği düşünülmüştür. Modifikasyon değerleri incelendiğinde madde 13 ile madde 16'nın modifikasyonlar arasında ki kare değerini en çok düşüren modifikasyon değeri olarak görülmüştür (24.6). Bir başka deyişle madde 13 (Konser ya da sinavlarda gösterdiğim performanstan sonra çevremden aldığım olumlu tepkiler iyi çalgı çalabildiğime olan inancımı arttırır) ile madde 16 (Çalg1 öğretmeninizin çalısınıza dair geri dönütleri iyi çalg1 çalabildiğinize ilişkin inancınızı ne kadar arttırıyor?) maddelerinin hataları arasında kovaryans tanımlaması yapılmasının ki kare değerini olumlu yönde etkileyeceği belirtilmiştir. Maddeler anlamsal olarak incelendiğinde her iki maddenin de anlamsal olarak birbirine yakın olduğu görülmektedir. Çünkü her iki madde de performansa ilişkin çevreden gelen dönütlerin iyi çalg1 çalmaya olan inancın artmasını etkilediğini belirtmektedir. Bu nedenle her iki madde arasında hata kovaryansları ilişkilendirildiğinde modelin daha iyi uyum iyiliği değerlerine sahip olduğu görülmektedir. Modifikasyondan sonra modelin elde ettiği değerler ise RMSEA $=0,058(\% 90$ Güven aralığ1 $=0,048-0,068)$, CFI $=, 93$, IFI $=$,93, AGFI $=, 87$, GFI $=, 90$ ve $\mathrm{RMR}=, 30$ 'dur. Modelin $\mathrm{x}^{2}$ değeri 283.52, serbestlik derecesi ise 148'tür. Ki kare değerinin serbestlik derecesine oranının 1.91 olması, bir başka deyişle 2'den az oluşu ise modelin iyi uyum sergilediğinin diğer bir kanıtı olarak gösterilebilir. Modele ilişkin diagram şekil 2'de sunulmuştur.

Şekil 2. Doğrulayıcı Faktör Analizi Diyagramı.

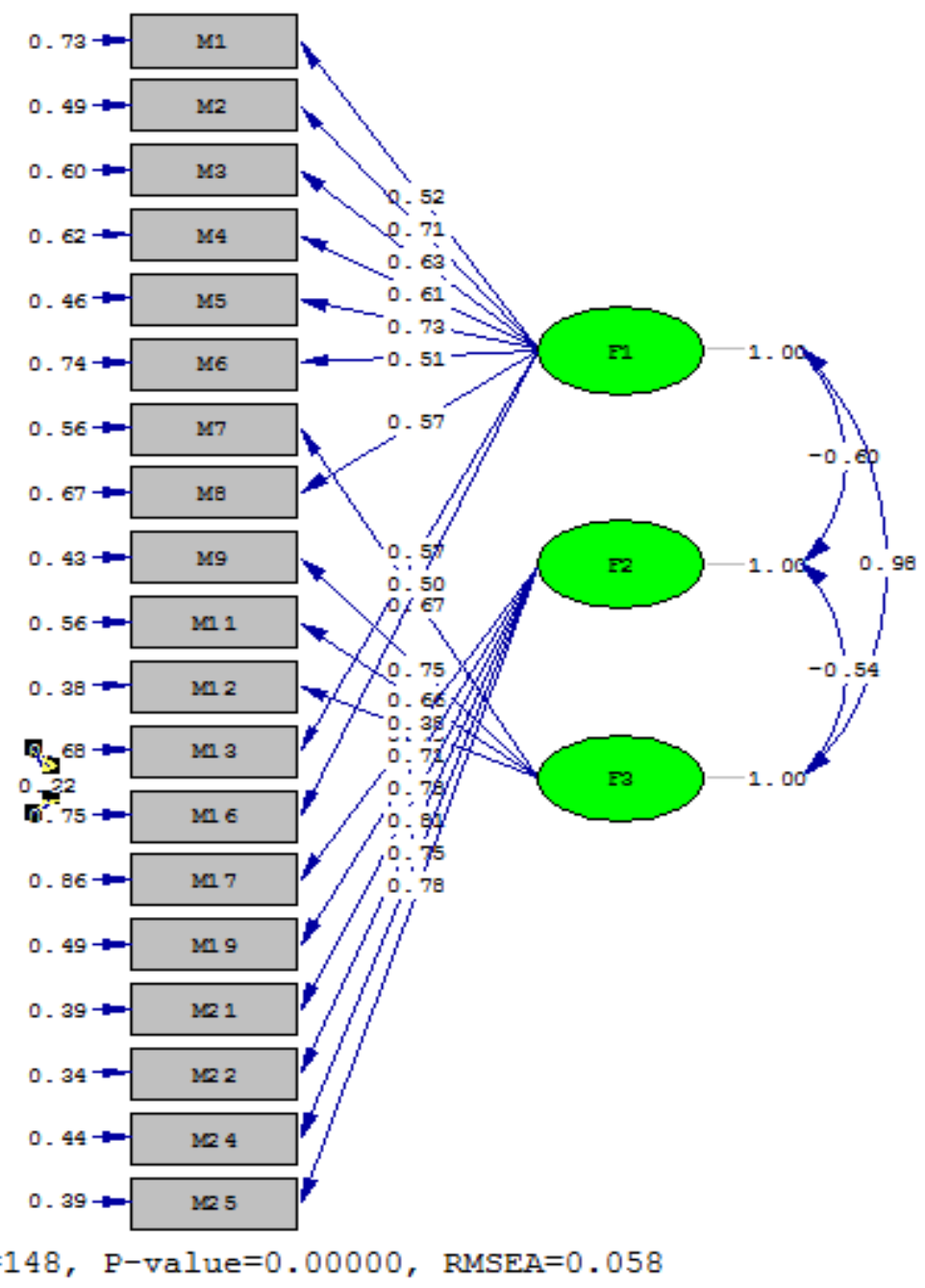

Chi-Square=283.52, df=148, P-value=0.00000, RMSEA=0.058 
Araştırmada diğer bir aşamada ölçeğin yakın ölçek geçerliği incelenmiş, 275 katılımcıya her iki ölçek uygulanarak toplam puanları üzerinden korelasyonları incelenmiş sonuçlar tablo 6'da sunulmuştur.

Tablo 6 Benzer Ölçek Geçerliği Analizi Sonuçları

\begin{tabular}{|c|c|c|c|c|c|c|c|c|c|}
\hline & & 1 & 2 & 3 & 4 & 5 & 6 & 7 & 8 \\
\hline 1 & ÇРÖYÖ & 1 & & & & & & & \\
\hline 2 & C.P.I.Ö. İ. & ,915** & 1 & & & & & & \\
\hline 3 & C.C.S.H.D.D &,$- 765 * *$ &,$- 494 * *$ & 1 & & & & & \\
\hline 4 & $M . A$ &, $844 * *$ &, $792 * *$ &,$- 436 * *$ & 1 & & & & \\
\hline 5 & ÇPÖİÖ & ,651** &, $596 * *$ &,$- 481 * *$ & ,584** & 1 & & & \\
\hline 6 & K.Y.G. &, $606^{* *}$ &, $586 * *$ &,$- 381 * *$ &, $594 * *$ &, $903 * *$ & 1 & & \\
\hline 7 & KYT.G &,$- 495^{* *}$ &,$- 426 * *$ &, $406 * *$ &,$- 408^{* *}$ &,$- 762^{* *}$ &,$- 571 * *$ & 1 & \\
\hline 8 & $P . G$ &,$- 355^{* *}$ &,$- 279 * *$ &, $392 * *$ &,$- 236 * *$ &,$- 560 * *$ &,$- 289 * *$ & ,473** & 1 \\
\hline
\end{tabular}

Tablo 6'da çalg1 çalışmaya ilişkin öz-yeterlik ölçeği (ÇPÖYÖ) nin benzer ölçek geçerliği analizi sonuçları verilmiştir. Bu sonuçlara her iki ölçeğin toplam puanları arasında pozitif yönde kuvvetli ilişki olduğu $(r=651, p<0,01)$ belirlenmiştir. Faktörel korelasyonlar incelendiğinde ise ÇPÖYÖ'nin "çalgisal performansa ilişkin öz-yeterlik inancı" alt boyutunun ÇPÖIÖ’nin "kendini yeterli görme" alt boyutu ile pozitif yönde kuvvetli ilişkiye $(r=586, p<0,01)$ yine aynı alt boyutun "kendini yetersiz görme" alt boyutu ile negatif yönde orta kuvvette ilişkiye $(r=-426, p<0,01)$ "psikolojik göstergeler" ile ise negatif yönde düşük kuvvette $(r=-279, p<0,01)$ sahip olduğu saptanmıştur. Aynı şekilde ÇPÖYÖ'nin "Çalg1 çalışma sırasında hissedilen negatif duygu durumları" alt boyutunun ise "kendini yeterli görme" ile negatif yönde orta kuvvette ilişkiye $(r=-381, p<0,01)$, "kendini yetersiz görme" alt boyutu ile pozitif yönde kuvvetli ilişkiye $(\mathrm{r}=406, \mathrm{p}<0,01)$, "psikolojik göstergeler" alt boyutu ile ise pozitif yönde orta kuvvette ilişkiye $(r=392, p<0,01)$ sahip olduğu görülmektedir. Ölçeğin 3. Faktörü olan "model alma" alt boyutunun "kendini yeterli görme "alt boyutu ile pozitif yönde kuvvetli ilişkiye ( $\mathrm{r}=594, \mathrm{p}<0,01)$, "kendini yetersiz görme" alt boyutu ile negatif yönde kuvvetli ilişki( $(\mathrm{r}=-408, \mathrm{p}<0,01)$ ve "psikolojik göstergeler" alt boyutu ile orta kuvvette negatif ilişki $(\mathrm{r}=-, 236, \mathrm{p}<0,01)$ içinde olduğu saptanmıştır.

Araştırmanın son aşamasında ölçek 17 gün arayla test-tekrar test ile sınanmıştır. Bu analiz için Adnan Menderes Üniversitesi Eğitim Fakültesi Güzel Sanatlar Eğitimi Bölümü Müzik Eğitimi Anabilim Dalı'ndan 68 kişilik katılımcı grubuna ölçek 17 gün arayla uygulanmıştır. Uygulama sonucunda iki ölçek arasında pozitif yönde kuvvetli ilişki saptanmıştır $(r=, 88, p<0,01)$. Elde edilen değer ölçeğin farklı zamanlarda uygulandığında tutarlığını koruduğu söylenebilir.

\section{TARTIŞMA}

Yapılan araştırmada eğitim fakültesi güzel sanatlar eğitimi bölümü müzik eğitimi anabilim dalı öğrencilerinin çalg1 performanslarına ilişkin öz-yeterlik düzeylerini ölçmek amacıyla geçerli ve güvenilir bir ölçek geliştirilmesi amaçlanmıştur. Araştırma sonucunda toplam 19 maddeden oluşan "çalgısal performansa ilişkin öz-yeterlik inancı", "Çalg1 çalışma sırasında hissedilen duygu durumları" ve "model alma" olmak üzere üç alt boyuta sahip ölçek elde edilmiştir. Geliştirilen ölçek toplam varyansın \%52,64'nü açıklamaktadır. Elde edilen üç alt boyutlu ölçeğin uyumu ise doğrulayıcı faktör analizi ile sınanmıştır. Modelin Ki kare değeri 283.52, serbestlik derecesi ise 148'dir. Ki kare değerinin serbestlik derecesine oranının 1.91 olması, bir başka deyişle 2'den az oluşu ise modelin iyi uyum sergilediğinin diğer bir kanıtı olarak gösterilebilir. Kline (2005) alan yazında küçük örneklemlerde $\mathrm{x}^{2} / \mathrm{df} \leq 2.5$ olabileceğini belirtmiştir. 
Ölçeğin güvenirliği incelendiğinde tüm ölçeğin Cronbach Alfa katsayısının .90, "çalgisal performansa ilişkin öz-yeterlik inancı" alt boyutunun.85, "Çalg1 çalışma sırasında hissedilen negatif duygu durumları" alt boyutunun ise .83 olduğu, "model alma" alt boyutunun ise ,76 olduğu belirlenmiştir. Elde edilen değerler, ölçeğin güvenilir olduğuna ilişkin kanıt olarak sunulabilir.

Ölçek daha sonraki aşamada girgin (2015) tarafından geliştirilen "Çalg1 performansı Öz-yeterlik Ölçeği” ile benzer ölçek geçerliği analizine tabi tutulmuştur. Analiz sonucunda her iki ölçeğin toplam puanlar arsında elde edilen pozitif yönde yüksek korelasyon $(r=651, p<0,01)$ ölçeğin benzer yapıları açıkladığının bir göstergesi olarak ifade edilebilir.

Diğer bir aşamada ölçeğin tutarllğını incelemek için test-tekrar test yapılmıştır. 68 kişilik katılımcı grubuna 17 gün arayla uygulanan ölçeğin tutarlık katsayısı $(r=.88, p<0,01)$ olarak bulunmuştur. Elde edilen bu değer ölçeğin farklı zamanlardaki uygulamalarda da tutarllık gösterdiğini belirtmektedir. Literatürde, bir ölçeğin zamana göre değişmez olduğunu saptamak üzere hesaplanan korelasyon katsayısının pozitif ve yüksek olmasının yanında ölçekler için bu değerin en az .70 olması istenmektedir (Tavşanc1l, 2002).

Geliştirilmiş olan ölçeğin en büyük özelliği, ulusal alan yazında bu alanda yapılmış olan ilk 0-10 cevaplamalı ölçek yapısına sahip olmasıdır. Bandura standart ölçümlerde 10’luk dilimlere bölünmüş olarak 0-100 araliklı cevaplamaların ya da daha basit olması gerekirse 0-10 aralıklı cevaplamaların kullanılması gerektiğini belirtmiştir. Bu cevaplamalarda " 0 " Yapamam, “50" orta seviyede yapabilirim ve "100" kesinlikle yapabilirim ifadelerini temsil etmektedir. Bandura az basamaklı ölçme araçlarından kaçınılması gerektiğini, çünkü bu tür araçların daha az hassas ve güvenilir olduklarını belirtmiştir. Pajares, Hartley, \& Valiante (2001) insanların az derecelemeye sahip ölçeklerde extrem noktaları işaretlemekten kaçındıklarını, az derecelendirmeye sahip ölçeklerde kişilerin farklı birbirlerinden az da olsa farklı cevaplar için aynı cevaplama basamaklarını kullandıklanını bu nedenle de ölçeğin ayırt edicilik özelliğini yitirdiğini belirtmiştir. Özellikle performansın belirlenmesinde 0-100 aralıklı ölçme araçlarının 5'li ölçme araçlarına göre daha güçlü belirleyiciler olduğu vurgulanmaktadır .

Çalg1 performansına ilişkin öz-yeterlik ölçeğinin geçerlik ve güvenirliğinin belirlenmesine yönelik bulgular birlikte değerlendirildiğinde ölçeğin eğitim fakülteleri güzel sanatlar eğitimi bölümleri müzik eğitimi anabilim dallarında öğrenim görmekte olan öğretmen adaylarının çalgı performanslarına yönelik öz-yeterlik düzeylerini belirlemekte geçerli ve güvenilir bir ölçek olduğu söylenebilir. Söz konusu ölçeğin mesleki müzik eğitimi veren diğer kurumlara uygulanması durumunda geçerlik ve güvenirlik kanıtlarının bu gruplar için tekrar test edilmesi yararlı olacaktır.

\section{Kaynakça}

Akbulut, E. (2013) Eğitim Fakültesi Müzik Eğitimi Anabilim Dalı "Bireysel Çalg1 Dersi Hedeflerinin Gerçekleşme Düzeylerine İlişkin 3. Ve 4.Sınıf Öğrencilerinin Görüşleri Açısından Bir Değerlendirme. Kastamonu Eğitim Dergisi, 21(1), 57-68.

Bandura, A. (1977). Self-efficacy: toward a unifying theory of behavioral change. Psychological review, 84(2), 191.

Bandura, A. (2006) Self-efficacy Beliefs of Adolescents. Information Age Publishing, Connecticut.

Büyüköztük, Ş. (2007) Sosyal Bilimler İçin Veri Analizi El Kitabı. Pegem Akademi Yayıncılık, Ankara. 
Büyüköztürk, S.., Akgün, Ö. E., Özkahveci, Ö., \& Demirel, F. (2004). Güdülenme ve öğrenme stratejileri ölçeğinin Türkçe formunun geçerlik ve güvenirlik çalışması. Kuram ve Uygulamada Eğitim Bilimleri, 4(2), 207-239

Çelik, E, H., Yılmaz, V. (2013) Yapısal Eşitlik Modellemesi. Anı Yayıncılık, Ankara.

Ericsson, K. A., Krampe, R. T., \& Tesch-Römer, C. (1993). The role of deliberate practice in the acquisition of expert performance. Psychological review, 100(3), 363.

Girgin, D. (2015) Çalg1 Performansı Özyeterlik İnanc1 Ölçeği: Geçerlik ve Güvenirlik Analizi. Pamukkale Üniversitesi Eğitim Fakültesi dergisi 38, 107-114.

Gün, E., Yıldız, G. (2014). Müzik öğretmeni adaylarına yönelik piyano performansı öz-yeterlik ölçeğiğnin geliştirilmesi. Turkish Studies, 9(5),1053-1065.

Kline, R. B. (2005). Principles and practice of structural equation modeling. NY: Guilford Publications, Inc.

McCormick, J., \& McPherson, G. (2003). The role of self-efficacy in a musical performance examination: An exploratory structural equation analysis. Psychology of Music, 31(1), 37-51.

McPherson, G. E., \& McCormick, J. (2006). Self-efficacy and music performance. Psychology of Music, 34(3), 322-336

Miksza, P. (2015). The effect of self-regulation instruction on the performance achievement, musical self-efficacy, and practicing of advanced wind players. Psychology of Music, 43(2), 219-243.

Özmenteş, S. (2007). Çalg1 çalışma sürecinde özdüzenlemeli öğrenme ile duyuşsal özellikler ve performans düzeyi ilişkileri. Yayımlanmamış doktora tezi, Dokuz Eylül Üniversitesi Eğitim Bilimleri Enstitüsü, İzmir.

Pajares, F. (1996). Self-efficacy beliefs in academic settings. Review of educational research, 66(4), 543-578.

Pajares, F., Hartley, J., \& Valiante, G. (2001). Response format in writing self-efficacy assessment: Greater discrimination increases prediction. Measurement and evaluation in counseling and development, 33(4), 214.

Pintrich, P. R. and De Groot, E. V. (1990) 'Motivational and Self-Regulated Learning Components of Classroom Academic Performance', Journal of Educational Psychology 82(1): $33-40$.

Rohwer, D., \& Polk, J. (2006). Practice behaviors of eighth-grade instrumental musicians. Journal of Research in Music Education, 54(4), 350-362.

Şimşek Ö. F. (2007) yapısal eşitlik modellemesine giriş temel ilkeler ve Lirel Uygulamaları. Ekinoks Yayınları, Ankara.

Tavşancıl, E. (2002). Tutumların Ölçülmesi ve SPSS’le Veri Analizi. Ankara: Nobel Yayınları.

Yıldırım, K. (2009). Kodaly Yönteminin İlköğretim öğrencilerinin keman çalma becerisi, özyeterlik alg1sı ve keman çalmaya ilişkin tutumları üzerindeki etkisi. Yayımlanmamış Doktora tezi. Dokuz Eylül Üniversitesi Ĕgitim Bilimleri Enstitüsü, İzmir.

\section{Extended English Abstract}

\section{Introduction}

Instrumental training can be defined as acquiring musical and technical skills needed for expressing musical expressions which are composed in one's mind. According to Akbulut (2013:58) instrumental training process is one of the important dimensions of both general and vocational music education and states that Instrument training is an effective process in acquiring individual musical attitudes, developing knowledge, skills and abilities and establishing a more strong connection with music. 
Of course, one of the biggest factors in the success of instrument training is the instrumental work process. Özmenteş (2007:1) express that instrumental training process needs intensive cognitive, affective, behavioral and social efforts along with musical talent. There is two key factor for successive instrumental training, one is the time devoting for practise and the other is how the time is configured by person. In literatüre many researchers emphasize that many musicians at a different level spend alot of time for personal practise. (McPherson, 2005, Sloboda, Davidson, Howe ve Moore, 1996; Sosniak; Byo ve Cassidy, 2008, Jorgensen, 1997; Miksza, 2015:219). But Rohwer \&Polk, (2006) and Miksza, (2015) stated that the amount of time spent for practise is not complete determinant of the performance success.

Pintrich and De Groot (1990:33) emphasize that cognitive and metacognitive knowledge is not sufficient for increase student achievement, motivational processes is necessary for effective use of cognitive and metacognitive strategies. Self-efficacy is the one of these motivatonal processess.

Self-efficacy which is the important part of Bandura's Social Cognitive Theory, is defined as beliefs in one's capabilities to organize and execute the courses of action required tomanage prospective situatons (Pajares, 1996:544). Özmenteş (2007), stated that student's self-efficacy beliefs towards their musical capabilities is one of the important factor which influence their self-regulated learning in their instrumental training. McCormick and McPherson (2003) also stated that self-efficacy is an important variable which influences the performance directly.

\section{Aim of the research}

In national literature, It appears that a small number of measuring instruments have been developed for measuring the self-efficacy level for instrumental performance. Self-efficacy scale for instrumental performance (Girgin,2015), Self-efficacy scale for piano performance (Gün ve Yildız, 2014) and Self-efficacy scale for violin performance (Ylldirm, 2009) can be given as an example. On the other hand, the fact that the number of valid and reliable measuring instruments in the field is large may allow a broader perspective of the self-efficacy level of instrument performance and will help to determine the factors which are influence this spesific self-efficacy field. The aim of trhis reearch is developing valid and reliable scale for measuring self-eficacy for instrumental performance.

\section{Method}

Scale development process is consist of expert overwiev, item analysis, explatory factor analysis, confirmatory factor analysis, reliability analysis, convergent validity and test re-test analysis.

In the research 26-item pre-test form was prepared and this form was presented to four expert in order to take their opinion about this form for it's content validity. Two of this experts are from department of guidance and psychological counseling and the others are in department of music eduation. According to experts opinions, 4 item were removed from scale and as a result of expert opinions, the form has been reduced to 22 items. In 22 -item form, 7 item is negative. In the form, items represent student's beliefs their instrumental performances, the beliefs about the effects of their past performances to their actual performances and beliefs about the feedbacks of the people in their surroundings about instrumental performances and the negative emotional situations felt during instrumental training.

The 22-item form was applied to 462 participant ( $\mathrm{n}=462)$ from four university, 19 persons who were found to be missing or incorrectly filled out forms were excluded from the data. The first 
analysis of the research is ite-analysis. The inter-item correlation and item-total correlation of 22 item were examined and 3 item which their item total correlations were found as insufficient.

After item analysis, exploratory factor analysis was applied.at the end of the results, three-factor structure obtained. This three factor were named as Self-efficacy for instrumental performance (factor 1), negative emotional state feeling during instrumental practise (factor 2) and modeling (factor 3). First factor explains $\% 36,6$ of total variance, second explains $\% 10,14$ and third factor explains $\% 5,8$ of total variance. Total scale explains $\% 52,64$ of total variance. The conbach-alpha coefficient of total scale is.90, first factor is.85, second factor is .83 and third factor's cronbachalpha coefficient is .76 . in the light of the sclae's analysis results obtained, tit can be said that the scale is reliable.

At the next stage of the research confirmatory factor analysis was examined. This analysis was applied to new participant group. $(n=275)$. The results of the analysis are RMSEA $=0,058(\% 90$ confidence interval $=0,048-0,068), \mathrm{CFI}=, 93, \mathrm{IFI}=, 93, \mathrm{AGFI}=, 87, \mathrm{GFI}=, 90$ ve $\mathrm{RMR}=, 30$. The chi-square of model is 283.52 , degre of freeedom is 148 . This results obtained can show us the three-factor structure is acceptable. In addition, the ratio of the chi-square value to the degree of freedom is 1.91, in other words, less than 2 , it can be shown as another proof that the model is well fit. With 275- participant data set, convergent validity was examined. For convergent validiy Girgin's (2015) sel-efficacy for instrumental peformance scale was used. As a result of the analysis, a strong and positive correlation coefficient was obtained $(\mathrm{r}=, 651, \mathrm{p}<0,01)$. In the ligt of the result, both scales can account similar constructs.

The last step of this research is test re-test for consistency of scale in different time periods. New dataset was collected from study group $(\mathrm{n}=68)$ who are student in Adnan Menderes University. Scale was applied to study group 17 day period. At the end of the test re-test analysis, positive and Strong correlation coefficient is obtained. This value indicates that the scale is also consistent in applications at different times.

\section{DISCUSSION}

The most important feature of this developed scale is the scale which has 0-10 responding ratio in musical self efficacy field in Turkish literature. Bandura (2006) stated that 0-10 responding ration scale should be used in standart measuring. In this mesuring " 0 " should represent "can not do at all", 5 should represent "moderately certain can do" and 10 should represent "Highly certain can do". Bandura also stated that it should be avoided measuring with a scales that use a fwe steps because they are less sensitive and less reliable. Pajares, Hartley, \& Valiante (2001) stated that people usually avoid the extreme positions so a scale with only a few steps may, in actual use, shrink to one or two points. mIncluding too few steps loses differentiating information because people who use the same response category may differ if intermediate steps were mincluded. Thus an efficacy scale with the 0-100 response format is a stronger mpredictor of performance than one with a 5-interval scale It is thought that the developed scale will provide important contributions to the literature. 